\title{
Adenosine $3^{\prime}, 5^{\prime}$ cyclic monophosphate attenuates the production of fibronectin in the glomeruli of anti-glomerular basement membrane antibody-associated nephritic rats
}

\author{
*,1Tadashi Nagamatsu, ${ }^{2}$ Tsutomu Nishiyama, ${ }^{1}$ Isamu Goto, ${ }^{1}$ Toshiyuki Nagao \& ${ }^{1}$ Yoshio Suzuki \\ ${ }^{1}$ Department of Pharmacology, Faculty of Pharmacy, Meijo University 150 Yagotoyama, Tenpakuku, Nagoya 468-8503, Japan \\ and ${ }^{2}$ Laboratory Animal Center, Taisho Pharmaceutical Co., LTD, 1-403 Yoshinocho, Saitama 330-0031, Japan
}

\begin{abstract}
1 Excessive production of extracellular matrix is thought to be involved in the progression of glomerulonephritis and glomerulosclerosis. In chronic glomerulonephritis, fibronectin has been shown to accumulate in the glomeruli, accompanied by cell proliferation.

2 Glomerulonephritis was induced in rats by the injection of anti-glomerular basement membrane antibody. The rats showed proteinuria and histological alterations in the glomeruli. An increase in fibronectin levels in the culture medium of isolated nephritic glomeruli was confirmed, and was associated with the development of nephritis. Immunohistochemical staining demonstrated a marked accumulation of fibronectin in the glomeruli of nephritic rats.

3 Attenuated generation of cyclic AMP was also observed in the nephritic glomeruli treated with forskolin, prostaglandin E1 or adenosine.

4 Forskolin, prostaglandin E2 and 8-bromo-cyclic AMP markedly reduced the production of fibronectin by the nephritic glomeruli compared with controls in a dose-dependent manner. 8-Bromocyclic AMP suppressed the production of fibronectin by cultured mesangial cells.

5 These findings suggest that the attenuated generation of cyclic AMP in response to ligands is connected to the augmented accumulation of fibronectin in nephritic glomeruli, and may facilitate the development of methods for treating glomerulonephritis and glomerulosclerosis.

British Journal of Pharmacology (2003) 140, 1245-1251. doi:10.1038/sj.bjp.0705564
\end{abstract}

Keywords: Nephritis; fibronectin; cyclic AMP; forskolin; prostaglandin E

Abbreviations: CAT, chloramphenicol acetyl transferase; CRE, cyclic AMP-response element; cyclic AMP, adenosine 3', 5' cyclic monophosphate; ELISA, enzyme-linked immunosorbent assay; PBS, phosphate-buffered saline; PGE 1 , prostaglandin $\mathrm{E}_{1} ; \mathrm{PGE}_{2}$, prostaglandin $\mathrm{E}_{2} ; \mathrm{RT}-\mathrm{PCR}$, reverse transcription polymerase chain reaction

\section{Introduction}

Mesangial alterations are common aspects of progressive glomerulonephritis. As selective permeability and microvascular structure in the glomeruli are partially maintained by mesangial cells and their extracellular matrix, alterations in the mesangium have been implicated in dysfunction of the kidneys. Excessive accumulation of extracellular matrix results in chronic renal failure. Extracellular matrix components have potentially important roles as receptors for adhesion, migration, proliferation and differentiation of constitutive cells and infiltrating cells in the glomeruli. The extracellular matrix also indirectly regulates the proliferation of such cells through the binding of growth factors. Fibronectin, one of the major components of the extracellular matrix, binds other extracellular matrix components such as collagen, heparin and fibrin, and adhesion molecules such as integrins onto the surface of cells. We considered that elucidation of the mechanisms underlying the regulation of fibronectin metabolism in the glomeruli is critical to the understanding of glomerulonephritis.

*Author for correspondence;

E-mail: nagamats@ccmfs.meijo-u.ac.jp

Advance online publication: 3 November 2003
Fibronectin is predominantly located in the mesangial area in the glomeruli. In various kidney diseases, fibronectin accumulates in the mesangial area, glomerular capillary loop and crescent formation in Bowman's space (Oberley et al., 1979; Weiss et al., 1979; Funabiki et al., 1990). Monocytes have been shown to invade the glomeruli of antiglomerular basement membrane antibody-induced nephritic rats (Hattori et al., 1994). Mosquera (1993) suggested that stimulators from macrophages were critical in enhancing the accumulation of fibronectin in injured glomeruli, because the production of fibronectin was increased in rat mesangial cells in the presence of culture medium containing activated abdominal macrophages. On the other hand, diabetes mellitus results in diffuse and nodular glomerulosclerosis. The incipient stage of diabetic nephropathy is characterized by capillary basement membrane thickening and expansion of the glomerular mesangium. The accumulation of fibronectin is commonly observed in diabetic nephropathy (Weiss et al., 1979). When cultured in the presence of a high concentration of glucose, mesangial cells increase the synthesis of extracellular matrix components, including fibronectin, as well as the expression of extracellular matrix mRNA (Ayo et al., 1990; 1991). 
Dean et al. (1988) demonstrated in human fibrosarcoma cell lines that transcription of the fibronectin gene became vigorous and biosynthesis of fibronectin increased in the presence of adenosine $3^{\prime}, 5^{\prime}$ cyclic monophosphate (cyclic AMP). A cyclic AMP-response element (CRE) is located upstream of the fibronectin gene (Dean et al., 1989). There are two additional low-affinity CREs in the $5^{\prime}$-flanking region of the fibronectin gene (Bowlus et al., 1991). Therefore, it is reasonable to conclude that cyclic AMP induces fibronectin biosynthesis. On the other hand, there is evidence that the glomeruli and cultured mesangial cells generate cyclic AMP in response to prostaglandins (Schlondorff et al., 1978), dopamine (Shultz et al., 1987), histamine (Sedor \& Abboud, 1985), adenosine (Abboud \& Dousa, 1983), or isoproterenol (Silbiger et al., 1994). Prostaglandin E1 and E2 (PGE 1 and $\mathrm{PGE}_{2}$ ) stimulate adenylate cyclase in isolated glomeruli (Schlondorff et al., 1978). Pharmacologically, there are four kinds of $\mathrm{PGE}_{2}$ receptor subtypes, namely $\mathrm{EP}_{1}, \mathrm{EP}_{2}, \mathrm{EP}_{3}$ and $\mathrm{EP}_{4}$, and the expression of mRNA for all the four receptor subtypes has been demonstrated in the kidney (Sugimoto et al., 1994; Nemoto et al., 1997). We have previously demonstrated the expression of mRNA for $\mathrm{EP}_{2}$ and $\mathrm{EP}_{4}$ in glomeruli by reverse transcription-polymerase chain reaction (RT-PCR) analysis (Nagamatsu et al., 2001). EP receptors have a seven-transmembrane structure and $\mathrm{EP}_{2}$ and $\mathrm{EP}_{4}$ are coupled to the $\mathrm{Gs}$ protein that stimulates adenylate cyclase. Therefore, we considered that $\mathrm{PGE}_{2}$-cyclic AMP is crucial for regulating the production of fibronectin in damaged glomeruli.

The aim of this study was to elucidate (1) how much cyclic AMP is generated in nephritic glomeruli following stimulation with various reagents, (2) the relationship between the production of fibronectin and cyclic AMP in nephritic glomeruli, and (3) whether the production of fibronectin is inhibited following cyclic AMP in mesangial cells. Nephritic glomeruli produced more fibronectin, and generated less cyclic AMP following stimulation with the reagents compared with the controls. This is the first study to reveal that the production of fibronectin is reduced by manipulations that increase intracellular cyclic AMP in nephritic glomeruli. The present findings may facilitate the development of methods for therapeutic intervention in glomerulonephritis.

\section{Methods}

\section{Animals}

Male Sprague-Dawley rats (Nihon SLC, Hamamatsu, Japan), weighing approximately $160 \mathrm{~g}$, were used in the experiments. These animals were housed in an air-conditioned room at $22^{\circ} \mathrm{C}$ with a $12 \mathrm{~h}$ light - dark cycle during the experimental period. Animals had free access to water and standard rat chow. All experiments were performed in accordance with the Guidelines for Animal Experiments of Meijo University Faculty of Pharmacy, the Guiding Principles for the Care and Use of Laboratory Animals approved by the Japanese Pharmacological Society, and the National Institutes of Health Guide for the Care and Use of Laboratory Animals.

\section{Reagents}

Rabbit gamma globulin, protease, collagenase type II, deoxyribonuclease, adenosine, 8-bromo-cyclic AMP, forskolin and 3-isobutyl-1-methylxanthine were purchased from Sigma Chemical Co. (St Louis, MO, U.S.A.); $\mathrm{PGE}_{1}$ and $\mathrm{PGE}_{2}$ were from Cayman Chemical (Ann Arbor, MI, U.S.A.), indomethacin, dimethyl sulfoxide and biotin-conjugated antimouse immunoglobulin $G$ polyclonal antibody were from Wako Pure Chemical (Osaka, Japan); N-2-hydroxyethylpiperazine- $N^{\prime}$-2-ethanesulfonic acid was from Dojin Chemical (Kumamoto, Japan); Hank's solution and RPMI 1640 were from Nissui Pharmaceutical (Tokyo, Japan); fibronectin and rabbit anti-rat fibronectin polyclonal antiserum were from Chemicon International (Temecula, CA, U.S.A.). Freund's complete adjuvant was purchased from Difco (Detroit, MI, U.S.A.); 3, 3'-diaminobenzidine tetrahydrochloride and streptavidin-conjugated horseradish peroxidase were from Vector Laboratories (Burlingame, CA, U.S.A.); Block Ace was from Dainippon Pharmaceuticals (Osaka, Japan); horseradish peroxidase-conjugated goat anti-rat fibronectin polyclonal antibody was from Calbiochem (La Jolla, CA, U.S.A.); fetal bovine serum was from CLS (Victoria, Australia); L-glutamine, penicillin-streptomycin, insulin-transferrin-seleniumA and trypsin-EDTA solution were from Life Technologies (Grand Island, NY, U.S.A.).

\section{Induction of anti-glomerular basement membrane antibody-associated nephritis}

To induce nephritis, rats were injected with $0.6 \mathrm{ml}$ of rabbit anti-rat glomerular basement membrane serum via the tail vein, followed by an injection of $6.5 \mathrm{mg}$ of rabbit gammaglobulin in $0.25 \mathrm{ml}$ of Freund's complete adjuvant into the hind footpads, in accordance with a previous method with slight modifications (Hayashi et al., 1994). Throughout the experiments, 24-h urine samples were collected by keeping each rat in an individual metabolic cage for $24 \mathrm{~h}$ on days 0,1 , 10, 20 and 30 after the injection of anti-glomerular basement membrane serum, and urinary protein was determined by a method reported previously (Nagamatsu et al., 1999). For light microscopy, the kidneys were isolated 30 days after the injection of anti-glomerular basement membrane serum. Paraffin sections of the kidneys were stained with Masson's trichrome.

\section{Accumulation of fibronectin in nephritic glomeruli}

Kidneys were isolated 30 days after the injection of antiglomerular basement membrane serum. Paraffin sections of the kidneys were stained immunohistochemically for fibronectin using a Vector Elite ABC Kit (Vector Laboratories). Briefly, deparaffinized kidney sections were treated with $0.1 \%$ protease in $0.05 \mathrm{M}$ Tris- $\mathrm{HCl}$ buffer for $7 \mathrm{~min}$, and washed in chilled $0.01 \mathrm{M}$ phosphate-buffered saline (PBS), $\mathrm{pH}$ 7.4. The sections were then incubated with blocking serum for $20 \mathrm{~min}$, and then with mouse anti-rat fibronectin polyclonal antibody $(1: 200)$ for $60 \mathrm{~min}$. The sections were washed again with $0.01 \mathrm{M}$ PBS, treated with $0.3 \%$ hydrogen peroxidase in methanol for $20 \mathrm{~min}$ to block endogenous peroxidase, and then incubated with biotin-conjugated anti-mouse immunoglobulin $\mathrm{G}$ polyclonal antibody $(1: 20)$ for $30 \mathrm{~min}$, followed by 
streptavidin-conjugated horseradish peroxidase. To visualize stained fibronectin, the sections were treated with $3,3^{\prime}$ diaminobenzidine tetrahydrochloride. All steps were carried out at room temperature.

\section{Isolation and incubation of the glomeruli (Mosquera, 1993)}

Kidneys were perfused with Hank's solution and then with $10 \%$ fetal bovine serum in RPMI 1640 via the abdominal aorta. The kidneys were removed and minced. The glomeruli were then isolated using a series of sieves (75-, 150- and 250- $\mu \mathrm{m}$ pore). The purity was more than $80 \%$, as determined by light microscopy. The glomeruli were incubated for $30 \mathrm{~min}$ at $37^{\circ} \mathrm{C}$ in RPMI 1640 containing deoxyribonuclease $\mathrm{I}\left(0.01 \mathrm{mg} / \mathrm{ml}^{-1}\right)$, collagenase type II $\left(25 \mathrm{U} / \mathrm{ml}^{-1}\right)$ and $1 \% \mathrm{~N}$-2-hydroxyethylpiperazine- $N^{\prime}$-2-ethanesulfonic acid for permeabilization. After washing, the glomeruli were suspended in $20 \%$ fetal bovine serum in RPMI 1640 at 2000 glomeruli ml ${ }^{-1}$. Aliquots of the suspension $(500 \mu \mathrm{l})$ were transferred to 24-well tissue culture plates (Nunc, Denmark) and $500 \mu$ l of RPMI 1640 or $250 \mu \mathrm{l}$ of RPMI 1640 plus $250 \mu \mathrm{l}$ of test reagent solution or vehicle were added. The glomeruli were incubated at $37^{\circ} \mathrm{C}$ for $48 \mathrm{~h}$ in $\mathrm{a} \mathrm{CO}_{2}$ incubator. After incubation, supernatants were obtained by centrifugation at $4^{\circ} \mathrm{C}$ for $5 \mathrm{~min}$ at 1000 r.p.m.

\section{Mesangial cell culture}

Mesangial cells were obtained by culturing the glomeruli isolated from the rat kidneys by a conventional sieving method (Kreisberg \& Karnovsky, 1983). Cells, grown in RPMI 1640 supplemented with $10 \mathrm{mmoll}^{-1} \mathrm{~N}$-2-hydroxyethylpiperazine$N^{\prime}$-2-ethanesulfonic acid, $2 \mathrm{mmoll}^{-1}$ L-glutamine, $100 \mathrm{U} \mathrm{ml}^{-1}$ penicillin-streptomycin and $20 \%$ fetal bovine serum, were identified by phase-contrast and immunofluorescence microscopy. They were characterized as intrinsic mesangial cells using previously reported criteria (Lovett et al., 1983). These criteria are (1) the presence of a spindle-shaped morphologic structure and the absence of polygon-shaped cells; (2) bright immunofluorescence staining for myosin, actin, desmin and Thy-1; and (3) negative staining for common leukocyte antigen, cytokeratin and factor VIII.

\section{Mesangial cell conditioning}

All experiments were performed using cells between the fifth and 10th passage. Mesangial cells $\left(2 \times 10^{4}\right.$ cells well $\left.^{-1}\right)$ were transferred to a 24-well tissue culture plate, and were incubated for $48 \mathrm{~h}$ in a $\mathrm{CO}_{2}$ incubator. After incubation, the culture medium was exchanged for serum-free medium containing fatty acid-free bovine serum albumin, and 8bromo-cyclic AMP or vehicle was added (Rovin et al., 1995). The mesangial cells were incubated for further $48 \mathrm{~h}$, and the culture medium was then extracted by centrifugation to determine the fibronectin concentration.

\section{Determination of fibronectin}

Fibronectin in the culture medium was determined by enzymelinked immunosorbent assay (ELISA). Briefly, rabbit anti-rat fibronectin polyclonal antiserum $(100 \mu \mathrm{l})$ was absorbed onto immunoplates (Nunc, Denmark) at $4^{\circ} \mathrm{C}$ for $12 \mathrm{~h}$. After blocking with Block Ace for $30 \mathrm{~min}$, the samples were added and incubated for $2 \mathrm{~h}$ at room temperature. They were then incubated with $100 \mu$ l of goat anti-rat fibronectin polyclonal antibody for $80 \mathrm{~min}$, followed by $100 \mu \mathrm{l}$ of horseradish peroxidase-conjugated rat anti-goat immunoglobulin $G$ antibody. Finally, $o$-phenylenediamine was added to visualize stained fibronectin at $37^{\circ} \mathrm{C}$. The fibronectin content in samples was obtained from a standard curve of rat fibronectin.

\section{Determination of cyclic AMP (Abboud \& Dousa, 1983)}

After isolation as described above, the glomeruli were suspended in Kreb's-Henseleit solution at 5000 glomeruli/ $200 \mu \mathrm{l}$. Another $200 \mu \mathrm{l}$ of Kreb's-Henseleit solution was added to the aliquots, which were then subjected to preincubation at $37^{\circ} \mathrm{C}$ for $20 \mathrm{~min}$. After preincubation, aliquots of $100 \mu \mathrm{l}$ of various test reagents or vehicle were added, and the tubes were then incubated for an additional $2 \mathrm{~min}$ at $37^{\circ} \mathrm{C}$. The incubation was terminated by the addition of $500 \mu \mathrm{l}$ ice-cold $10 \%$ trichloroacetic acid and immediate homogenization with a Teflon pestle. The homogenate was centrifuged at 5000 r.p.m. for $20 \mathrm{~min}$ and the supernatant was used to determine cyclic AMP by radioimmunoassay (cyclic AMP assay kit, Yamasa, Chiba, Japan).

\section{Statistical analysis}

Results are expressed as the mean \pm s.e.m. The data were analyzed by one-way analysis of variance (ANOVA) or the Kruskal-Wallis test. Analyses for statistical significance were carried out with Student's $t$-test. To determine the significance of differences among groups, Bonferroni's procedure was used. Differences between the mean values of the experimental and control groups were considered significant at $P<0.05$.

\section{Results}

Anti-glomerular basement membrane antibody-associated nephritis

Massive amounts of protein were excreted into the urine 1 day after the injection of anti-glomerular basement membrane serum, and proteinuria continued to increase thereafter (Figure 1A). On day 30, nephritic glomeruli showed an expanded mesangial area and thickening of the capillary walls compared with the normal control glomeruli. As shown in Figure 1B-b, crescent formation was observed in the Bowman's space in some nephritic glomeruli.

\section{Accumulation of fibronectin in nephritic glomeruli}

When the isolated glomeruli were incubated, more fibronectin accumulated in the culture medium of the nephritic glomeruli than in control cultures (Figure 1C). The production of fibronectin was significantly increased 10 days after the injection of anti-glomerular basement membrane serum. On day 30, nephritic glomeruli produced six-fold higher levels of fibronectin than the normal control. Additionally, immunohistochemical staining of kidney sections revealed an increase in fibronectin expression in the glomeruli of nephritic rats. Capillary walls and the mesangial area were strongly stained 

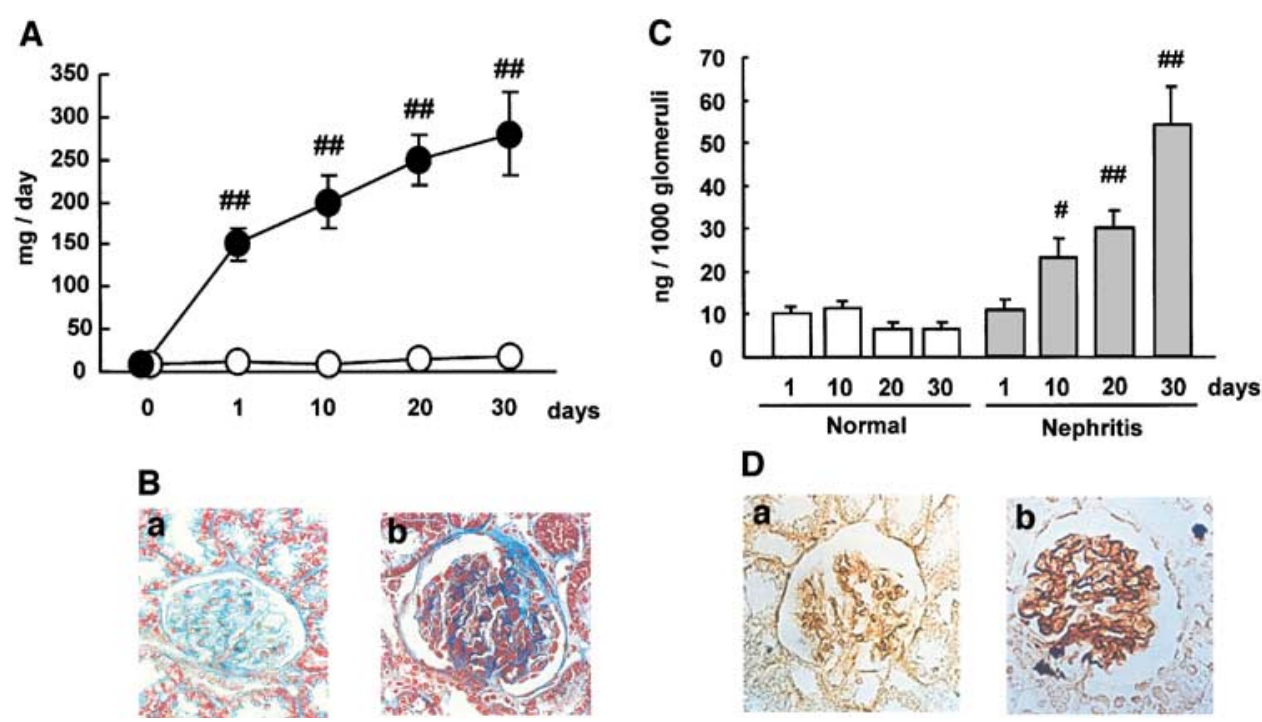

Figure 1 (A) Time course of proteinuria. Urine samples were obtained before and after injection of anti-glomerular basement membrane serum. Open circles indicate the normal control, closed circles indicate the nephritic rats. Data are shown as the mean \pm s.e.m. $N=7-10$. \#\# indicates significant difference from the normal control. (B) Photographs of the normal glomerulus (a) and the nephritic glomerulus (b). Kidneys were isolated 30 days after injection of anti-glomerular basement membrane serum. Kidney sections were stained with Masson's trichrome. Note the expanded mesangial area and thickening glomerular capillary lumen in (b). (C) Production of fibronectin in nephritic glomeruli. The glomeruli were isolated after injection of anti-glomerular basement membrane serum. The glomeruli were incubated for $48 \mathrm{~h}$. Each column indicates the mean \pm s.e.m. $N=6-8$. \# and \#\# indicate significant differences from the corresponding normal glomeruli at $P<0.05$ and 0.01 , respectively. (D) Photographs of fibronectin in the normal glomerulus (a) and the nephritic glomerulus (b). Kidneys were isolated 30 days after injection of antiglomerular basement membrane serum. Kidney sections were immunohistochemically stained with anti-fibronectin serum. Fibronectin was detected in the capillary lumen and mesangial area. Note the expanded positive area for fibronectin in the nephritic glomerulus (b) compared with the normal control (a).

with anti-rat fibronectin antibody in all the glomeruli of nephritic mice, as shown in Figure 1D-b.

\section{Production of cyclic AMP in nephritic glomeruli by pharmacological manipulation}

Cyclic AMP production in nephritic glomeruli was $44 \%$ of that in normal glomeruli in response to $10^{-6} \mathrm{M}$ forskolin (Figure 2a). PGE $_{1}$ and adenosine augmented cyclic AMP production in both normal and nephritic glomeruli in a dosedependent manner. In normal glomeruli, $10^{-5} \mathrm{M} \mathrm{PGE}_{1}$ caused a five-fold higher level of cyclic AMP generation compared with vehicle-treated controls (Figure 2b), and $5 \times 10^{-4} \mathrm{M}$ adenosine induced a three-fold increase in the cyclic AMP levels (Figure 2c). Although the nephritic glomeruli produced double the amount of cyclic AMP in response to $10^{-5} \mathrm{M} \mathrm{PGE}_{1}$ compared with vehicle-treated nephritic controls, the levels of cyclic AMP were similar to those of the vehicle-treated normal control glomeruli (Figure 2b). The production of cyclic AMP was significantly less in the nephritic glomeruli compared with the normal glomeruli following treatment with $5 \times 10^{-4} \mathrm{M}$ adenosine (Figure 3c).

\section{Production of fibronectin in forskolin-, $P G E_{2}-$ or 8-bromo-cyclic AMP-treated nephritic glomeruli}

We investigated the effects of forskolin on the production of fibronectin in the nephritic glomeruli because forskolin stimulates adenylate cyclase directly. At $10^{-6} \mathrm{M}$ forskolin decreased the levels of fibronectin by $42 \%$ compared with the vehicle-treated control nephritic glomeruli (Figure 3a). As the kidney produces large amounts of $\mathrm{PGE}_{2}$, not $\mathrm{PGE}_{1}$ and the glomeruli express prostaglandin E receptor subtypes $\left(\mathrm{EP}_{4}\right)$ (Nagamatsu et al., 2001), we investigated the effects of $\mathrm{PGE}_{2}$ on fibronectin production in the nephritic glomeruli. The accumulation of fibronectin decreased dose-dependently in the nephritic glomeruli incubated with $\mathrm{PGE}_{2}$ compared with the vehicle-treated nephritic controls (Figure 3b). $\mathrm{PGE}_{2}$ at a concentration of $10^{-7} \mathrm{M}$ resulted in a $29 \%$ reduction in the production of fibronectin in the nephritic glomeruli. Finally, to clarify the effect of cyclic AMP on the production of fibronectin in the nephritic glomeruli, 8-bromo-cyclic AMP was added to the culture medium of the nephritic glomeruli. Significantly less fibronectin accumulated in the glomeruli in response to $10^{-9} \mathrm{M}$ 8-bromo-cyclic AMP, and the magnitude of suppression depended on the concentration of 8-bromo-cyclic AMP (Figure 3c). The levels of fibronectin were decreased to $54 \%$ of the vehicle-treated control glomeruli following treatment with $10^{-6} \mathrm{M}$ 8-bromocyclic AMP.

\section{Effects of 8-bromo-cyclic AMP on the production of fibronectin in cultured mesangial cells}

The glomeruli consist of a few different cell types. Mesangial cells are representative of those able to produce fibronectin in the glomeruli. In the present study, we obtained mesangial cells from rats to evaluate whether 8-bromo-cyclic AMP suppresses the production of fibronectin by cultured mesangial cells. In mesangial cells treated with $10^{-6} \mathrm{M} 8$-bromo-cyclic AMP, the levels of fibronectin were $18 \%$ less than in the vehicle-treated control cells (Figure 4). 


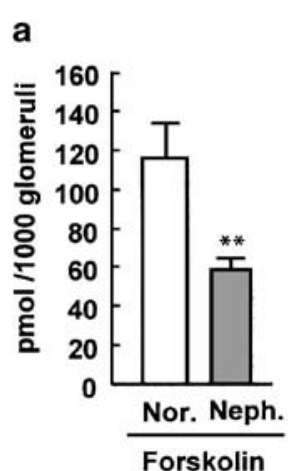

b

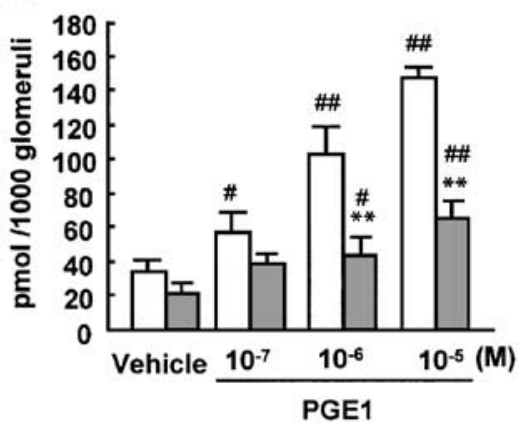

C

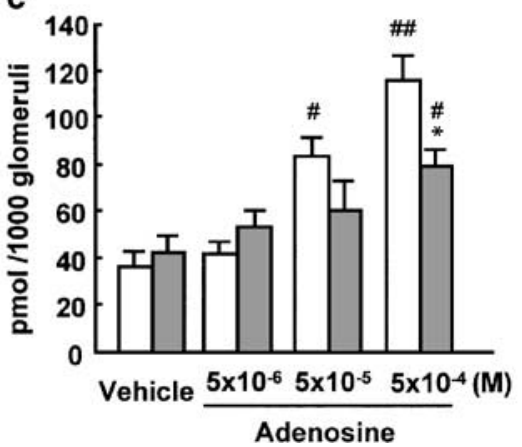

Figure 2 Production of cyclic AMP in nephritic glomeruli by pharmacological manipulation. The glomeruli were isolated 20 days after injection of anti-glomerular basement membrane serum. Open columns indicate the normal control glomeruli, closed columns indicate the nephritic glomeruli. Each column indicates the mean + s.e.m. $N=6-10$. $*$ and $* *$ indicate significant differences from the normal glomeruli at $P<0.05$ and 0.01 , respectively. \# and \#\# indicate significant differences from the corresponding vehicle controls at $P<0.05$ and 0.01 , respectively.

\section{Discussion}

We have confirmed that isolated nephritic glomeruli increase the production of fibronectin with the development of nephritis, and we have also demonstrated using immunohistochemical techniques that fibronectin accumulates in nephritic glomeruli. The nephritic glomeruli generated less cyclic AMP than the normal glomeruli, when incubated in the presence of various agents that increase the cyclic AMP levels. Forskolin, $\mathrm{PGE}_{2}$ and 8-bromo-cyclic AMP markedly attenuated the production of fibronectin in the nephritic glomeruli.

We speculate that there are several possible causes of the impaired generation of cyclic AMP in the nephritic glomeruli observed in the present study. The production of cyclic AMP seems to be reduced in the glomeruli of pathological models including the present nephritic model. In the puromycin aminonucleoside-induced nephrotic model, the glomeruli show a reduction in the accumulation of cyclic AMP and inositol phosphates on incubation with $\mathrm{PGE}_{2}$ compared with controls. As phosphatidylinositol breakdown in the glomeruli is accelerated in response to $\mathrm{PGE}_{2}$ compared with that in controls, and dibutyryl cyclic AMP inhibits $\mathrm{PGE}_{2}$-induced phosphatidylinositol breakdown, $\mathrm{EP}_{2}$ - and $\mathrm{EP}_{4}$-receptor subtypes may be affected in the glomeruli with nephrosis (Watanabe, 1990). Although we have not reported any data, we have observed a decrease in the expression of $\mathrm{EP}_{2^{-}}$and $\mathrm{EP}_{4^{-}}$ receptor subtype mRNA in the glomeruli in antiglomerular a

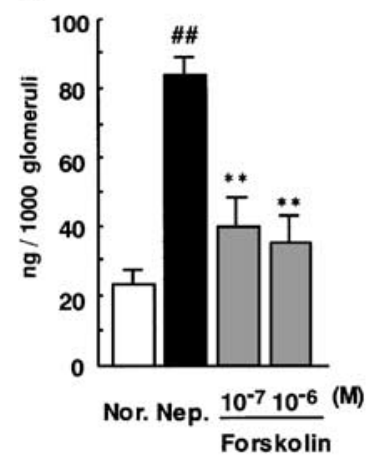

b

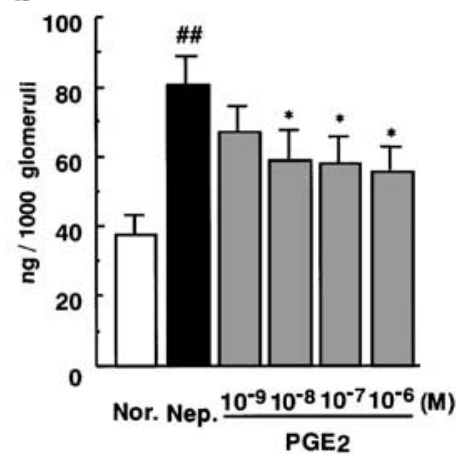

C

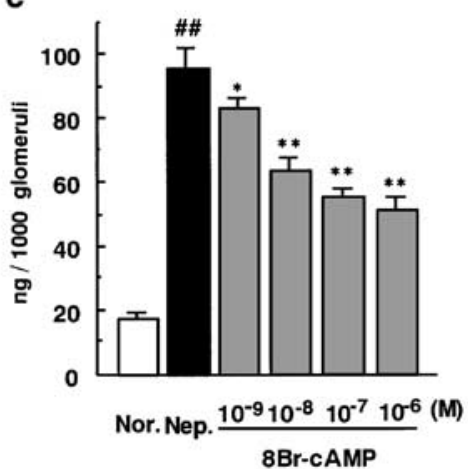

Figure 3 Effects of forskolin (a), $\mathrm{PGE}_{2}$ (b) and 8-bromo-cyclic AMP (c) on fibronectin production in nephritic glomeruli. The glomeruli were isolated 20 days after injection of anti-glomerular basement membrane serum. Each column indicates the mean \pm s.e.m. $N=6-10$. \#\# indicates a significant difference from the normal glomeruli (Nor.) at $P<0.01$. * and ** indicate significant differences from the nephritic controls (Nep.) at $P<0.05$ and 0.01 , respectively.

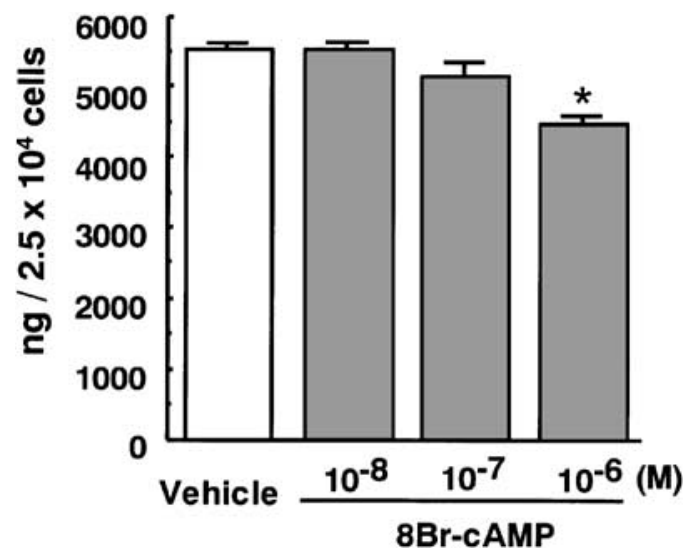

Figure 4 Effects of 8-bromo-cyclic AMP on fibronectin production by cultured mesangial cells. Mesangial cells were incubated with vehicle or 8-bromo-cyclic AMP for $48 \mathrm{~h}$. Each column indicates the mean \pm s.e.m. $N=4$. * indicates a significant difference from the vehicle control at $P<0.05$.

basement membrane antibody-associated nephritic mice, measured by RT-PCR analysis. The accumulation of cyclic AMP in response to isoproterenol has been shown to decrease the glomeruli of spontaneously diabetic rats, even though the level of cyclic AMP accumulation in diabetic glomeruli was equal to that induced in control glomeruli by $\mathrm{PGE}_{2}$ or 
histamine (Silbiger et al., 1994). When the diabetic glomeruli were incubated with forskolin, no differences in the cyclic AMP levels between the control and diabetic rats were observed; nor were any differences in glomerular $\beta$-adrenoceptor number and affinity between the control and diabetic rats detected (Silbiger et al., 1994). Therefore, in this diabetic model, dysfunction of Gs protein was considered to be the cause of the reduced accumulation of cyclic AMP in the glomeruli. Furthermore, in the glomeruli from ligated kidneys, accumulation of cyclic AMP was reduced in responses to $\mathrm{PGE}_{2}$ or parathyroid hormone compared to the contralateral glomeruli. As nephritic glomeruli produced less cyclic AMP in response to forskolin in the present experiments, we considered that (1) the activity of adenylate cyclase was inhibited, (2) the expression of adenylate cyclase was suppressed, or (3) the levels of substrates for adenylate cyclase were lower in nephritic glomeruli. Further studies are needed to clarify the mechanism behind the reduction in glomerular cyclic AMP accumulation in experimental nephritis.

In the additional experiments with cultured mesangial cells, we reproduced previous findings that 8-bromo-cyclic AMP suppresses the biosynthesis of fibronectin by nephritic glomeruli. Rovin et al. (1995) observed a suppressive effect of 8-bromo-cyclic AMP on the production of fibronectin by cultured human mesangial cells. Since the cultured human mesangial cells were incubated for $48 \mathrm{~h}$ with 3-isobutyl-1methylxanthine plus 8-bromo-cyclic AMP, the magnitude of the suppressive effect of 8-bromo-cyclic AMP was greater than the effect we observed. These findings suggest that the fibronectin produced by isolated glomeruli is partially derived from mesangial cells, and agonists stimulate the mesangial cells in the isolated glomeruli. They also support our idea that the increase in fibronectin production in nephritic glomeruli is induced by inadequate generation of cyclic AMP. We are now investigating why nephritic glomeruli generate less cyclic AMP than normal glomeruli in the presence of agonists, despite higher levels of $\mathrm{PGE}_{2}$.

In the present study, more fibronectin accumulated in the nephritic glomeruli than in the controls, although the production of cyclic AMP was lower in the nephritic glomeruli. In addition, forskolin, 8-bromo-cyclic AMP and $\mathrm{PGE}_{2}$ decreased the production of fibronectin in the nephritic glomeruli. These results seemed to be in conflict with previous findings that forskolin, 8-bromo-cyclic AMP and 3-isobutyl-1methylxanthine produced an increase in fibronectin biosynthesis and fibronectin mRNA in fibrosarcoma (HT-1080) and choriocarcinoma (JEG-3) cell lines (Dean et al., 1988). Dean et al. found the largest increase in fibronectin biosynthesis 24 - $48 \mathrm{~h}$ after incubation in a combination of forskolin and 3isobutyl-1-methylxanthine. There are three CREs in the $5^{\prime}$ flanking region of the fibronectin gene (Dean et al., 1988; Bowlus et al., 1991). Gonadotropin-releasing hormone promotes fibronectin secretion in granulose cells (Dorrington \&
Skinners, 1986), while follicle-stimulating hormone suppresses fibronectin production to undetectable levels. In addition, follicle-stimulating hormone abolishes the action of gonadotropin-releasing hormone on fibronectin production (Dorrington \& Skinners, 1986). Interestingly, both dibutyryl cyclic AMP and 3-isobutyl-1-methylxanthine mimic the action of folliclestimulating hormone, that is, reducing the production of fibronectin and abolishing the action of gonadotropin-releasing hormone on fibronectin production (Dorrington \& Skinners, 1986). Follicle-stimulating hormone induces an increase in the cyclic AMP levels in rat granulosa cells (Epstein-Almog \& Orly, 1985). In addition, follicle-stimulating hormone and dibutyryl cyclic AMP decrease fibronectin mRNA levels in a bovine granulose cell line (BGC-1) (Bernath et al., 1990). In BGC-1 cells, Bernath et al. (1990) found that the inhibitory effect of cyclic AMP requires $48 \mathrm{~h}$ incubation, upstream sequences other than CRE, located between positions -510 and -223 of the fibronectin gene, and is dependent on de novo protein synthesis. They also found that, when chloramphenicol acetyl transferase (CAT) activity is assayed in BGC-1 cells transiently transfected with fibronectin promoterCAT constructs $24 \mathrm{~h}$ after incubation with dibutyryl cyclic AMP, a stimulatory effect of dibutyryl cyclic AMP is observed, which is the same whether the constructs contain or lack the -150 to -223 region. Dean et al. (1988) also reported that treatment of the human cell lines TE671, HeLa and FS-1 with forskolin for $48 \mathrm{~h}$ resulted in fibronectin biosynthesis rates that were even lower than basal levels, suggesting differences in responsiveness to cyclic AMP among cell lines and/or feedback mechanisms. Furthermore, Rovin et al. (1995) observed a significant increase in fibronectin production by cultured human mesangial cells after a $2 \mathrm{~h}$ incubation with 8-bromo-cyclic AMP and, in contrast, a decrease in fibronectin production after a $48 \mathrm{~h}$ incubation. Therefore, we speculated that the upstream region of the fibronectin promoter in the glomeruli has a similar sequence to that in BGC-1 cells. Further investigations are required to determine what protein is expressed following long-term exposure to cyclic AMP and what DNA sequence is responsible for the protein expression.

Taken together, these observations suggest that suppression of the $\mathrm{PGE}_{2}$ - cyclic AMP response in nephritic glomeruli is required to increase the production of extracellular matrix and to promote recovery from injury during the early stages of glomerulonephritis. However, if excessive production of extracellular matrix continues due to continuing low levels of cyclic AMP, mesangial expansion occurs in the injured glomeruli. The present findings may facilitate the development of methods for therapeutic intervention in glomerulonephritis.

This study was supported in part by a grant-in-aid for Scientific Frontier Research Project of Meijo University from the Ministry of Education, Culture, Sports, Science and Technology of Japan.

\section{References}

ABBOUD, H.E. \& DOUSA, T.P. (1983). Action of adenosine on cyclic $3^{\prime}, 5^{\prime}$-nucleotides in glomeruli. Am. J. Physiol., 244, F633-F638.

AYO, S.H., RADNIK, R.A., GARONI, J.A., GLASS, W.F. \& KREISBERG, J.I. (1990). High glucose causes an increase in extracellular matrix proteins in cultured mesangial cells. Am. J. Pathol., 136, 1339-1348.
AYO, S.H., RADNIK, R.A., GLASS, W.F., GARONI, J.A., RAMPT, E.R., APPLING, D.R. \& KREISBERG, J.I. (1991). Increased extracellular matrix synthesis and mRNA in mesangial cells grown in high-glucose medium. Am. J. Physiol., 260, F185-F191 
BERNATH, V.A., MURO, A.F., VITULlO, A.D., BLEY, M.A., BARANAO, J.L. \& KOMBLIHTT, A.R. (1990). Cyclic AMP inhibits fibronectin gene expression in a newly developed granulosa cell line by a mechanism that suppresses cAMP-responsive element-dependent transcriptional activation. J. Biol. Chem., 265, $18219-18226$.

BOWLUS, C.L., MCQUILLAN, J.J. \& DEAN, D.C. (1991). Characterization of three different elements in the $5^{\prime}$-flanking region of the fibronectin gene which mediate a transcriptional response to cAMP. J. Biol. Chem., 266, 1122-1127.

DEAN, D.C., BLAKELEY, M.S., NNEWBY, R.F., GHAZAL, P., HENNIGHAUSEN, L. \& BOURGEOIS, S. (1989). Forskolin inducibility and tissue-specific expression of the fibronectin promoter. Mol. Cell. Biol., 9, 1498-1506.

DEAN, D.C., NEWBY, R.F. \& BOURGEOIS, S. (1988). Regulation of fibronectin biosynthesis by dexamethasone, transforming growth factor beta, and cAMP in human cell lines. J. Cell Biol., 106, $2159-2170$.

DORRINGTON, J.H. \& SKINNERS, M.K. (1986). Cytodifferentiation of granulosa cells induced by gonadotropin-releasing hormone promotes fibronectin secretion. Endocrinology, 118, 2065-2071.

EPSTEIN-ALMOG, R. \& ORLY, J. (1985). Inhibition of hormoneinduced steroidogenesis during cell proliferation in serum-free cultures of rat granulosa cells. Endocrinology, 116, 2103-2112.

FUNABIKI, K., HORIKOSHI, S., TOMINO, Y., NAGAI, Y. \& KOIDE, H. (1990). Immunohistochemical analysis of extracellular components in the glomerular sclerosis of patients with glomerulonephritis. Clin. Nephrol., 34, 239-246.

HATTORI, T., NAGAMATSU, T., ITO, M. \& SUZUKI, Y. (1994). Contribution of ED-1- and CD-8-positive cells to the development of crescentic-type anti-GBM nephritis in rats. Nippon Jinzo Gakkai Shi, 36, $1228-1239$.

HAYASHI, K., NAGAMATSU, T., ITO, M., HATTORI, T. \& SUZUKI, Y. (1994). Acteoside, a component of Stachys Sieboldii MIQ, may be a promising antinephritic agent (2): effect of acteoside on leukocyte accumulation in the glomeruli of nephritic rats. Jpn. J. Pharmacol., 66, $47-52$.

KREISBERG, J.I. \& KARNOVSKY, M.J. (1983). Glomerular cells in culture. Kidney Int., 23, 439-447.

LOVETT, D.H., RYAN, J.L. \& STERZEL, R.B. (1983). A thymocyte-activating factor derived from glomerular cells. J. Immunol., 130, 1796-1801.

MOSQUERA, J.A. (1993). Increase production of fibronectin by glomerular cultures from rats with nephrotoxic nephritis. Macrophages induce fibronectin production in cultured mesangial cells. Lab. Invest., 68, 406-412.
NAGAMATSU, T., HAYASHI, K., OKA, T. \& SUZUKI, Y. (1999). Angiotensin II type I receptor antagonist suppresses proteinuria and glomerular lesions in experimental nephritis. Eur. J. Pharmacol., 347, 93-101.

NAGAMATSU, T., NAGAO, T., KOSEKI, J., SUGIURA, M., NISHIYAMA, T. \& SUZUKI, Y. (2001). Involvement of prostaglandin $E_{2}$ clearance of aggregated protein via protein kinase A in glomerulus's. Jpn. J. Pharmacol., 85, 139-145.

NEMOTO, K., PILBEAM, C.C., BILAK, S.R. \& RAISZ, L.G. (1997) Molecular cloning and expression of a rat prostaglandin $\mathrm{E}_{2}$ receptor of the $\mathrm{EP}_{2}$ subtype. Prostaglandins, 54, 713-725.

OBERLEY, T.D., MOSHER, D.F. \& MILLS, M.D. (1979). Localization of fibronectin within the renal glomerulus and its production by cultured glomerular cells. Am. J. Pathol., 96, 651-662.

ROVIN, B.H., TAN, L.C., LEONHART, K.L. \& NANMAN, N.S. (1995). Cyclic adenosine monophosphate and protein kinase $\mathrm{C}$ modulate fibronectin production in cultured human mesangial cells. J. Lab. Clin. Med., 126, 216-223.

SCHLONDORFF, D., YOO, P. \& ALPERT, B.E. (1978). Stimulation of adenylate cyclase in isolated rat glomeruli by prostaglandins. Am. $J$. Physiol., 235, F458-F464.

SEDOR, J.R. \& ABBOUD, H.E. (1985). Histamine modulates contraction and cyclic nucleotides in cultured rat mesangial cells Differential effects mediated by histamine $\mathrm{H} 1$ and $\mathrm{H} 2$ receptors. J. Clin. Invest., 75, 1679-1689.

SHULTZ, P.J., SEDOR, J.R. \& ABBOUD, H.E. (1987). Dopaminergic stimulation of cAMP accumulation in cultured rat mesangial cells. Am. J. Physiol., 253, H358-H364.

SILBIGER, S.R., COHEN, A.J., FISHMAN, J.B. \& STOFF, J.S. (1994) Defective glomerular beta-adrenergic signal transmission in spontaneously diabetic rats. J. Lab. Clin. Med., 124, 249-254.

SUGIMOTO, Y., NAMBA, T., SHIGEMOTO, R., NEGISHI, M., ICHIKAWA, A. \& NARUMIYA, S. (1994). Distinct cellular localization of mRNAs for three subtypes of prostaglandin E receptor in kidney. Am. J. Physiol., 266, F823-F828.

WATANABE, H. (1990). A study of $\mathrm{PGE}_{2}$-induced signal transduction in aminonucleoside nephrosis. Nippon Jinzo Gakkai Shi, 32, 1187-1194 ( Japanese ).

WEISS, M.A., OOI, B.S., OOI, Y.M., ENGVALL, E. \& RUOSLAHTI, E. (1979). Immunofluorescent localization of fibronectin in the human kidney. Lab. Invest., 41, 340-347.

(Received June 10, 2003 Revised September 16, 2003 Accepted September 30, 2003) 